\title{
Agent-based modelling of immigration impact
}

Policy makers depend on immigration policies and quotas, derived from models of the impacts of immigration Marcello Marini, Dr Ndaona Chokani and Professor Reza S. Abhari from the Laboratory for Energy Conversion (LEC) Group, at ETH Zürich have developed an artificia intelligence model that significantly reduces simulatio times allowing for higher Switzerlynd as their test case, their agent-based modelling demonstrates the impact of immigration on demographics, urban infrastructures and the social security needs of the whole society. to design policies that meet

n Switzerland, $80 \%$ of the annual population growth is a result of immigration. Consequently, foreign
nationals make up $25 \%$ of Switzerland's resident population. Migration often Tas be beneficial in a country where, in the last century, the proportion of residents over the age of 65 has risen from $5.8 \%$ to $17.8 \%$, and the proportion of those over 80 has increased from $0.5 \%$ to $5.0 \%$ Moreover, there are concerns that the Swiss social security system is at risk if there is insufficient growth in the labour force to cover the cost of supporting social security insurances, such as pension funds and occupational benefit plans, an ageing population.

The European Commission deems the issue of demographic ageing as policies that meet the nning. Designing entire society hower, is a daunting

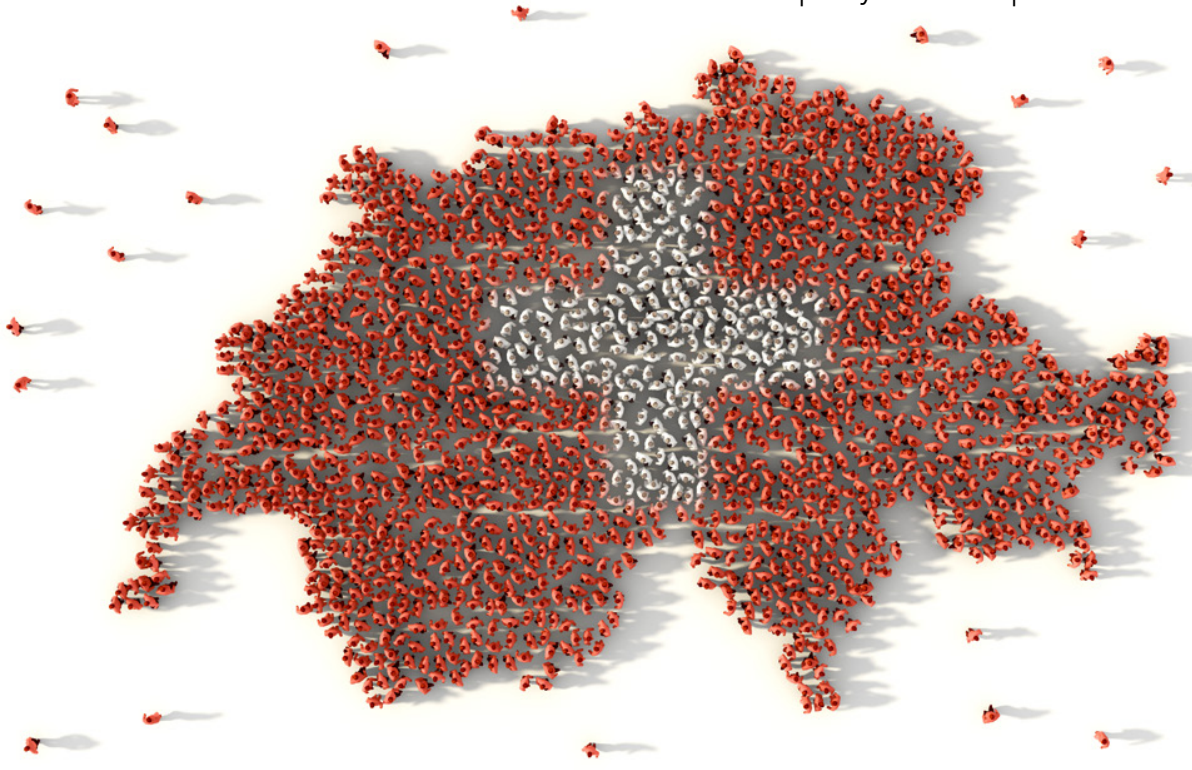

immigration policies and quotas, derive from models of immigration impact, rol demographics.

Classical modelling methods based on past trends rarely account for future changes in population and economy, or changes resulting from more approaches permit the simulation of complex systems but require the collection and standardisation of huge amounts of data so generating results within a reasonable timeframe is challenging and often results are compromised by reducing complexity, the number of time intervals and/or the spatial extent of the simulation.

Marcello Marini, a PhD student with the Laboratory for Energy Conversion TeC) Group, at he Institute of Energy DrNology, ETH Zunich, together with LEC Group, ETH Zürich, and Professor Reza S. Abhari, Director of the LEC ETH Zürich, has developed an artificia intelligence model that significantly reduces simulation times allowing for higher complexity and the extension to full-country scale.

\section{A NEW AGENT-BASED MODE} Agent-based modelling, where

population agents represent

members of the population, simulates interactions between agents as well as interactions between agents and their environment. The research team have created an agent-based simulation detailing population, buildings, mobility infrastructure and energy infrastructure,

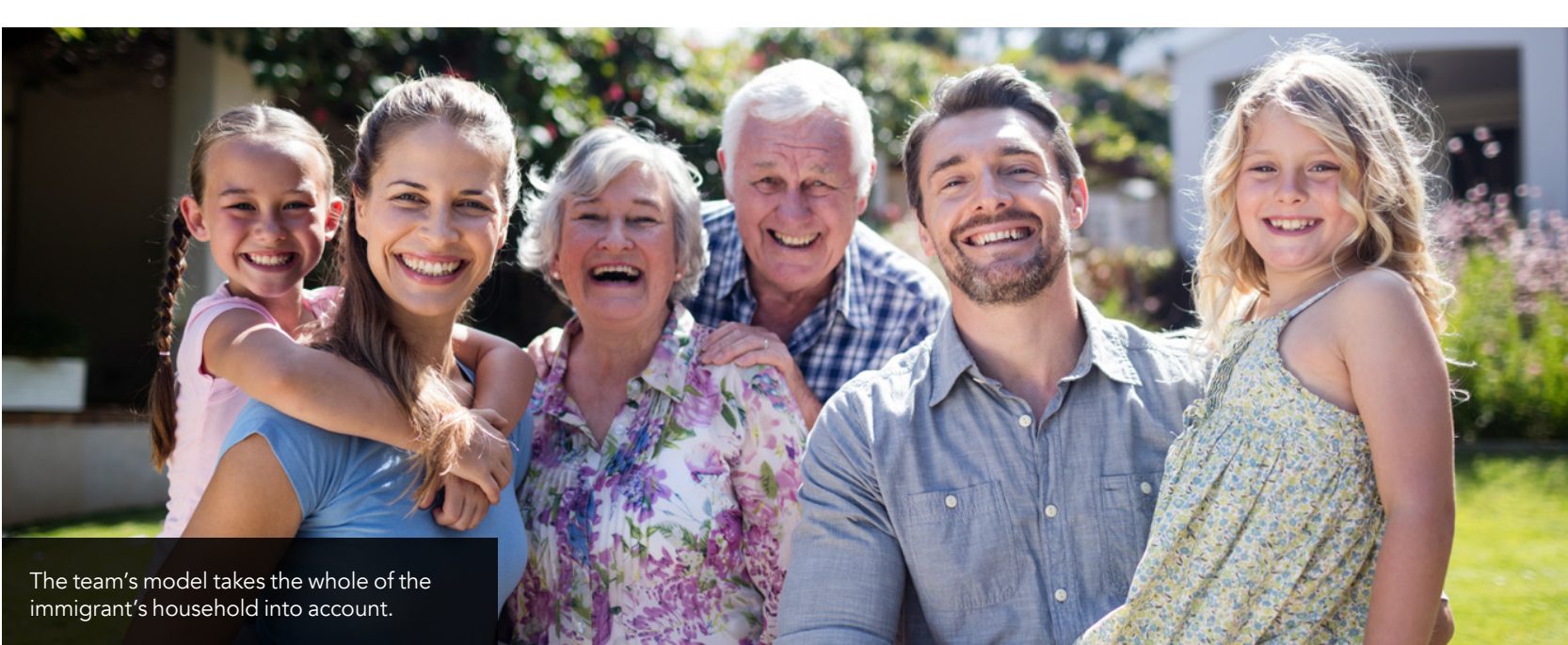

covering the geographic extent of Europe. They also employ Graphica Processing Unit (GPU) computer Processing Unit (GPU) computer ducing complexity or scale.

The researchers have extended the EnerPol, developed in-house at the LEC, with a dynamic agent-based population model that dynamically simulates the individual life cycle and choices of agents, together with the formation and depending on the agent's satisfaction, income and house-to-work distance. The relocation submode initiates on their for households depending ond cost of the dwelling and house-towork distance. Migrating agents are exogenously specified in the migration submodel which determines the number and size of immigrating and emigrating households each year. New agents are added to the simulation and assigned jobs and dwellings depending on their households' characteristics. transformation of their household, taking Throughout these submodels, a GPUeconomic, geographic, and urban factors accelerated choice model provides

\section{THREE SCENARIO}

The researchers set up three scenarios: the "business as usual" scenario is ands of mojection of the historical the Swiss Federal Office for Statistics: the 'large families' scenario involves a transformation in the structure of immigrants' households that assumes a move towards larger families with children; and the 'demographic stagnation' scenario, considers a possible eaction to the increase in migration, by limiting the number of immigrants to $50 \%$ of those in the business as usual scenario, keeping the net migration quota at

$$
40,000-50,000
$$

SUBMODELS The outcomes from the agent-based individuals peryear initial population immigration could address the long- distributions an

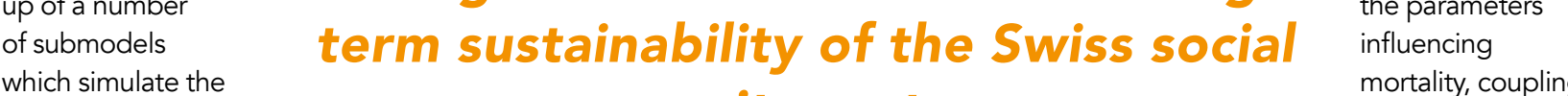

\section{annual evolution \\ security system.}

of the population

up to a target year. The ageing and deathing submodel increases an agent's age with each simulated year. Agents' deaths occur with a probability based on their age and gender. The coupling, offspring, and uncoupling submodel also depend on probabilities. The probability of coupling is a function of marital status, age, and employment status. The probability of offspring for each household depends on the age the woman and the current number for houren. The chance of uncoupling for households is computed for a proportion of couples The job change for fast computations of the available choices for agents. SIMULATION

chose to use the population of Switzerland as a test case so that they could examine the impact of possible future migration A digital coun actual population. A digital country twin was created, enabling them to determine the impact of migration on the social security cash impacting immigration, thus influencin impacting immigration, natality rates

were based on historical data and were the same for the three scenarios. The transportation infrastructure remained unchanged throughout the simulation period which ran from 2014 to 2035

The research team examined the impacts of the three different immigration scenarios on the Swiss social security system's solvency. They discovered that if annual immigration rates were So be limited to $50 \%$ of today's rate, be insolvent by 2027. If immigrem would are tailored to favor bra immigrant 
ENERGY

PEOPLE FLOW \& MOBILITY POPULATION URBAN PUBLIC TRANS
NOISE EMISSIONS

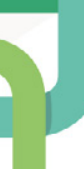

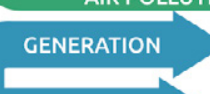

TRANSMISSION

DEMAND

RELOCATION

The model outcomes have highlighted the impact of immigration on both the demands for suitable housing and urban development.

families with children, however, the esearchers found that the social security system would be more sustainable.

the researchers carried out further

The outcomes from the agent-based simulations demonstrate how managing inmigration could address the long-term sustainability of the Swiss social security system. These simulations show how the birth rate could increase with immigrant populations, thus mitigating the effect of the current ageing population. The total population, however, would be greater than if immigration was restricted so there for housing and services.

\section{IMMIGRATION AND FUTUR}

Texplore the impact of demographic

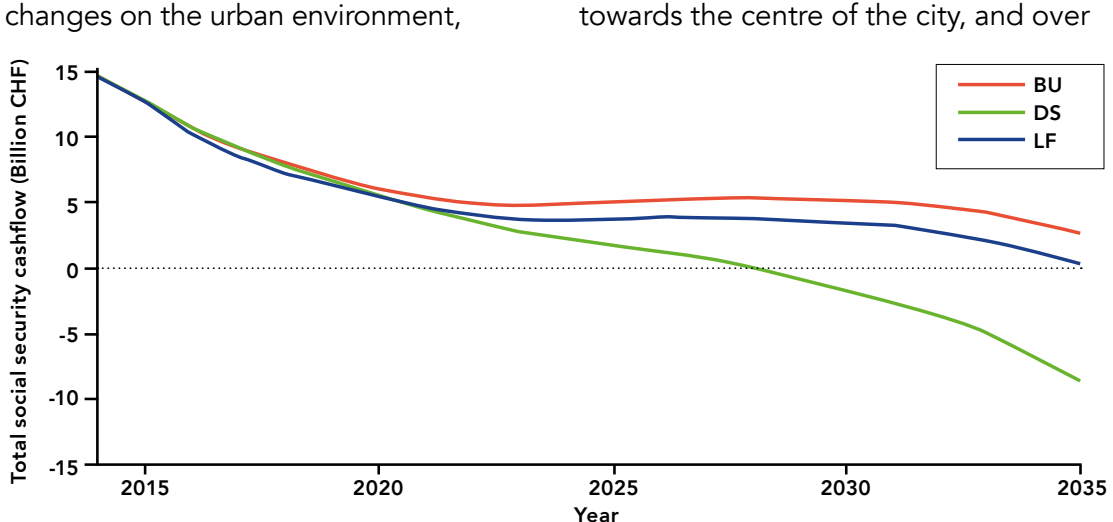

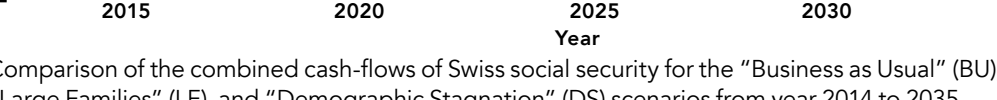

Theloop of factors includedn he model.

Population (Today)

\begin{tabular}{c}
\hline \\
Coupling, Offspring, \\
Uncoupling \\
$\downarrow$ \\
Job Change \\
$\downarrow$ \\
Relocation \\
$\downarrow$ \\
Migration \\
Loop \\
\hline
\end{tabular}

Population (Future)

time, the simulations show an increase in the numbers of family households when compared with numbers of singles and couples households.

These simulations demonstrate a requirement for more services in the periphery of Lausanne to be aimed at the increasing demographic of smaller households. Furthermore, the majority of workplaces would still be situated in the city centre, so when planning improvements to the transportation infrastructure, the intial focus should be on improved

\section{RESEARCH OUTCOMES}

The research team have shown how their artificial intelligence agentresolution spatial analysis ranging from a single dwelling to an entire country. They can quantify the impact of immigration on demographics and urban infrastructures. The mode outcomes have highlighted the impact of immigration on both the demands for suitable housing and urban development as well as the long-term sustainability of the country's social security system. Moreover, they have cemonstrated how agent-based model can support the design of policies that address the relative prosperity and social

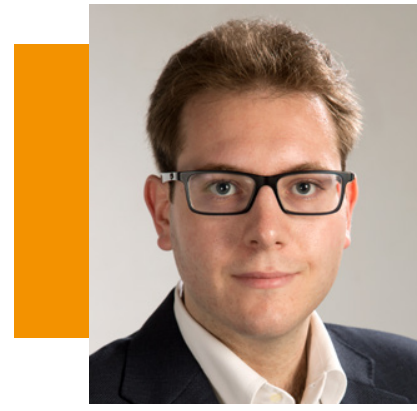

\section{Behind the Research} Marcello Marini

Marcello Marini and colleagues have developed a simulation frame
of immigration.

\section{Detail}

\section{Marcello Marini}

stitut für Energietechnik, LEC

ETH Zürich, ML H 39

Sonneggstrasse
$\mathrm{CH}-8092$ Zürich

Switzerland

\section{Bio}

Marcello Marini has been a PhD student at ETH Zürich since 2015. His research focuses on the developmen and application of agent-based models and the use of GPU hardware for fast computations. His broad range of multidisciplinary work includes demographics and traffic infrastructure, migration and jobs,

\section{Ndaona Chokani}

Dr Ndaona Chokani holds a PhD in Engineering He was a professor for 17 years in the USA. Since 2006, he has worked at ETH Zurich, where he leads the group that has developed EnerPol, an agent-based sim and systems, modelling, and agent-based modelling.

Reza S. Abhari

Prof Reza S. Abhari has, since 1999, been full professor of energy technologies and Director of Laboratory for Energy Conversion (LEC) at ETH Zurich. Following his PhD at MIT, he held various senior research positions in industry. LEC focuses on developing break-through technologies for a

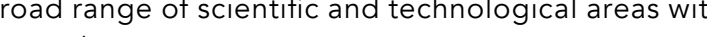
societal impact.

EHzürich

\section{References}

Marini, M., Chokani, N., Abhari, R. (2019). Immigration and future housing needs in Switzerland: Agentbased modelling of agglomeration Lausanne. 78, 101400. Available at: https:///doi.org/10.1016/j. compenvurbsys.2019.101400

Marini, M., Chokani, N., Abhari, R. (2018). AgentBased Model Analysis of Impact of Immigration on Migration and Integration. 20,787-808. Avalable https://doi.org/10.1007/s12134-018-0631-8

Marini, M., Gawlikowska, A., Rossi, A., Chokani, N., Klumpner, H., Abhari, R. (2018). The impact of future cities on commuting patterns: An agent-based approach. Environment and Planning B: Urban Analytics and City Science, 46(6), 1079-1096. Available at:

\section{Personal Response}

What advice would you give to policy makers II Policy makers should not focus on 'simplistic' solutions to the immigration question, such as specific quotas, but rather focus on typologies of immigrant As an example, we have demonstrated that on one hand more family-friendly immigration policies increase the natural growth of the existing population. On the other hand, family-friendly policies attract migrants composed term, as opposed to single-household workers whose primary goals include a return to their home countries. As a consequence, family-friendly immigration policies yield an investment in the future that makes the support
of workforce and social security more sustainable. 